\title{
O GRAFEMA DAS ESCRITAS NÃO-FONÉTICAS: HIEROGLIFO, PICTOGRAMA, LOGOGRAMA, IDEOGRAMA?
}

\author{
Elisa Figueira de Souza Corrêa* \\ (Universidade do Estado do Rio de Janeiro)
}

\begin{abstract}
Resumo: Este artigo examina quatro termos diferentes comumente utilizados para se referir aos grafemas de escritas não-fonéticas: pictograma, hieroglifo, logograma e ideograma. Faz-se a revisão das definições mais comuns a fim de estabelecer diferenças e semelhanças entre os termos e, na fixação de limites, defende-se a continuação da terminologia "ideograma" para os caracteres chineses em uso, mormente, na China e Japão, para marcar suas próprias peculiaridades.
\end{abstract}

Palavras-chave: escrita não-fonética; hieroglifo, pictograma, logograma, ideograma

\section{NON-PHONETIC WRITING GRAPHEMES: HIEROGLYPH, PICTOGRAM, LOGOGRAM, IDEOGRAM?}

\begin{abstract}
This article examines four different terms commonly used to refer to graphemes of non-phonetic writing: pictogram, hieroglyph, logogram and ideogram. The most common definitions are reviewed in order to establish differences and similarities between the terms and, by setting limits, the continuity of the term "ideogram" is advocated for the Chinese characters in use, mainly in China and Japan, as a mark of its own peculiarities.
\end{abstract}

Keywords: non-phonetic writing; hieroglyph, pictogram, logogram, ideogram

\section{Introdução}

A definição de "língua" não é fácil, mas a das formas e unidades usadas nos sistemas de escrita das línguas tampouco. Em especial, no caso das formas de escrita não-fonéticas, muita confusão ocorre entre a variedade de sistemas de escrita e como se referir a seus caracteres.

Naturalmente, percebe-se que as pessoas têm a tendência de confundir a forma de escrita das línguas que não entendem - o que faz algum sentido. No entanto, mesmo os que estudam línguas não-fonéticas por vezes ficam confusos sobre qual seria a forma correta de denominarem cada unidade daquela escrita.

Talvez por isso seja cada vez mais comum ouvir pessoas que, embora não saibam japonês, usam a palavra japonesa "kanji" em vez do vocábulo português "ideograma". A globalização permitiu a circulação maior de palavras e conhecimento, mas esse circunlóquio não resolve a questão: o que é um ideograma? E ainda: um kanji é um ideograma?

Proponho, então, que se reflita a seguir sobre alguns dos tipos de escrita não-fonética e seus grafemas (unidades de escrita), para tentar diferenciar essas denominações e esclarecer certos pontos.

\footnotetext{
*E-mail: elisa.correa@uerj.br
} 


\section{A invenção da escrita e os pictogramas}

Tomemos "escrita" como a notação da palavra escrita e nada (ou quase nada) além disso, como propôs Mark Weeden $(2014$, p. 82). Isso significa que ela é precedida pela fala e a ela está ligada. Logo, é importante notar que a escrita existe para representar coisas que estão ausentes, isto é, é formada por sinais (signos linguísticos) em um sistema de representação simbólica (SOARES; BATISTA, 2005).

As primeiras formas de escrita são provavelmente derivadas de desenhos primitivos que foram sendo simplificados e sistematizados com o tempo. Ou seja, existe diferença entre um sistema de escrita e os desenhos encontrados em cavernas. Observe-se a imagem a seguir:

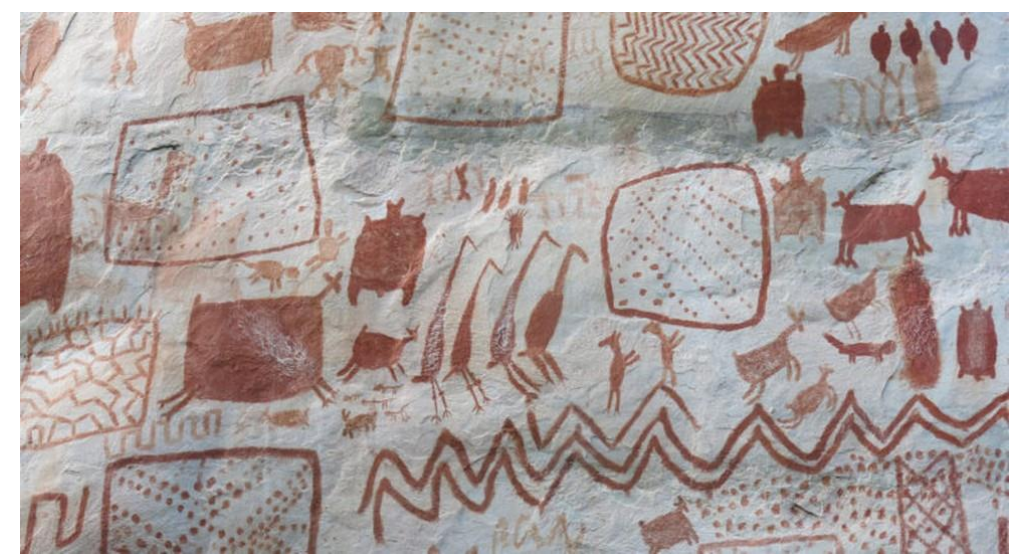

Figura 1. Foto de Francisco Javier Aceituno Bocanegra/Museu Britânico. Fonte: https://g1.globo.com/ciencia-esaude/noticia/2020/12/04/exploradores-descobrem-pinturas-da-era-do-gelo-na-amazonia-colombiana.ghtml

Trata-se de uma pintura rupestre na Serranía la Lindosa, na Colômbia, descoberta em 2019. Nela são facilmente identificáveis várias figuras similares que podem se referir a uma mesma estrutura (talvez um campo arado) ou a animais de uma mesma espécie. Ainda assim, porém, não é possível associar essas figuras repetidas a pictogramas, pois para isso seria preciso retirar desse conjunto de imagens "frases", i.e., uma comunicação estruturada, o que é facilmente perceptível quando sua repetição é consistente, como acontece na fala. Por exemplo, quantas vezes, neste parágrafo apareceu a vogal "a" ou a palavra "um"? A repetição ordenada de itens permite identificar uma estruturação. A organização espacial das frases (linhas verticais ou horizontais, ou ainda a escrita circular) também é outro ponto importante que não se vê na foto acima.

Mais do que isso, as próprias figuras acima, para se tornarem pictogramas, precisariam ser codificadas e mais padronizadas. Embora haja diferença entre a caligrafia de uma pessoa e outra, existe um número limitado de variações para que se possa identificar um "a" como "a". A letra "e" é parecida com a letra "a", mas justamente o limite que existe fixado em nossa cultura das variações caligráficas faz com que ambas não sejam consideradas a mesma letra. Esse fato é verdade para letras, mas também para qualquer grafema de qualquer língua. Observe-se, por exemplo, como os seguintes ideogramas são parecidos, mas não são iguais: 大 太 犬. A diferença de um traço, marca a distinção entre os três e essa consistência na escrita faz com que eles deixem de ser um mero "desenho" e passem a ser um grafema, um signo linguístico. Kate Clair e Cynthia Busic-Snyder (2009, p. 13) sintetizaram bem essa característica: "a essência de um sistema de escrita é a repetição de formas de uma maneira combinada. Para que possam comunicar, os desenhos simplificados precisam ser reconhecíveis e facilmente interpretados por um maior número de pessoas". 
No entanto, é inegável que foram esses mesmos desenhos rupestres que, com o tempo, foram sendo consistentemente padronizados e codificados na forma de escrita. Quando isso aconteceu, formaram-se então os primeiros hieroglifos, logogramas e ideogramas.

Os registros de escrita mais antigos do mundo são considerados como os da escrita cuneiforme na Suméria (região da Mesopotâmia, Oriente Médio), datados de 3.200 a.C. Outras escritas antigas são os hieroglifos egípcios (3.000 a.C.) e o sânscrito (1.500 a.C.). A escrita chinesa também é muito antiga. Os registros mais antigos largamente aceitos remontam a 1.800 a.C., porém escavações entre 2003-2006 encontraram artefatos de 7.000 a.C. com símbolos que já lembram a escrita moderna (cf. LI et al., 2003). Sendo milhares de anos mais antigas que todas as demais escritas conhecidas, muito se têm questionado se essas marcas já retratariam um período de real "escrita" da língua chinesa, ou se seriam apenas sinais - como nós marcamos, por exemplo, "perigo" ou "veneno" com um desenho de "caveira com ossos cruzados". Outros pesquisadores, todavia, insistem que já há ali pequenas sequências evidenciando palavras (TANG, 2013).

De toda forma, seja escrita ou não, a similaridade desses símbolos encontrados na região de Jiahu (China) com os caracteres modernos serve para apontar, sem dúvida, um passo na evolução da História da escrita humana: a transição de um mero símbolo indicando alguma coisa, para a junção de vários deles tentando formar palavras e frases.

É possível considerar pictogramas simples símbolos. Se pensarmos dessa forma, o exemplo acima do símbolo de "veneno" é um pictograma. Muitos símbolos que usamos no dia a dia também: um cigarro cortado em um restaurante, uma figura feminina na porta de um banheiro, uma lupa em um website. Todas essas imagens são capazes de nos transmitir idéias precisas, porque já são pictogramas convencionais na nossa sociedade; mas, na verdade, como afirma Mark Weeden (2014, p. 81) os pictogramas nem sempre têm uma "concretização lexical", isto é, não têm uma tradução precisa em uma palavra (ou frase) como uma palavra de verdade.

Além disso, esse tipo de pictograma não é padronizado nem simplificado o suficiente para refletir, como os sistemas de escrita, a estruturação da nossa comunicação em sua forma mais completa - não permitem processos de formação de palavras, flexões de número, de gênero, de tempo, não se unem em frases ${ }^{1}$ etc. Por isso, existe esse questionamento e relutância entre aceitar os achados de Jiahu como pictogramas ou "escrita".

Nem por isso pode-se dizer que os pictogramas não comunicam. Eles refletem algo da nossa linguagem e tanto é assim que deram origem outros tipos de grafemas e permanecem existindo como comunicação imagética hoje.

\section{Logogramas e hieroglifos}

A definição de "logograma" mais aceita parece ser a de Weeden $(2014$, p. 81), segundo a qual um logograma é um grafema que expressa, independentemente da língua, uma palavra inteira. Segundo essa definição nossos algarismos são logogramas: para o símbolo "2" associamos palavras como "dois", "two", "deux" etc.

Ainda segundo Weeden (2014, p. 81), os ideogramas seriam uma subespécie dos logogramas. O ideograma é um grafema que expressa uma palavra (ou um conjunto de palavras conceitualmente relacionadas) por meio de um signo que é ele mesmo conceitualmente relacionado a qualquer palavra que ele possa expressar. Como exemplo, Weeden apresenta a

\footnotetext{
${ }^{1}$ Não estou tentando afirmar com isso que todas as línguas possuem sistemas de escrita que transparecem todos os fenômenos morfossintáticos nelas existentes.
} 
idéia do ideograma PÉ2 significando "andar", “ficar de pé”, “correr”. Outro exemplo que podemos trazer é o do ideograma $日$ que pode ser traduzido como ou relacionado às idéias de “sol”, “dia” e “Japão"; ou 明 que pode ser "luz”, “claro", “brilhante”, “alegre”, “abrir”, "seguinte" - apenas a situação e/ou o uso continuado irá definir qual o sentido empregado.

$\mathrm{Na}$ verdade, atualmente a idéia de uma escrita totalmente conceitual como sugere a palavra "ideograma" (dos radicais gregos para "idéia" + "letra") tem sido bastante questionada. David Olson (2014), por exemplo, nota com relação à escrita da língua chinesa que, por se acreditar originalmente que os grafemas da escrita chinesa eram "motivados" (ou seja, lembram dado objeto), acreditava-se que também a língua chinesa "representava idéias mais do que estruturas", diferentemente de outras línguas.

Essa idéia hoje é sabidamente falsa. Um ideograma não remete a uma "unidade de pensamento", mas a uma "unidade linguística", a qual pode ou não ser uma palavra completa. Irei tratar com mais detalhes dos ideogramas depois, na penúltima seção do texto, mas, inicialmente, é preciso notar que o sistema de escrita com ideogramas da língua chinesa e da língua japonesa é complexo, tanto quanto eram os das escritas hieroglíficas.

Sobre os hieroglifos, Andrew Robinson (1823, apud GERBER, 2009) explica:

O sistema de escrita [hieroglífica] é uma mistura de símbolos semânticos, isto é, símbolos que correspondem a palavras e ideias, também conhecidos por logogramas, e símbolos fonéticos, fonogramas, que correspondem a um ou mais sons (alfabéticos ou policonsonantais). Alguns hieroglifos são figuras reconhecíveis de objetos, um pássaro ou uma serpente, isto é, eles são pictogramas, mas a figura (picture) não revela necessariamente o sentido do signo.

Ou seja, se consideramos um determinado hieroglifo, percebe-se que ele tem múltiplas funções. Sua forma pode ser "motivada" (um pictograma), mas isso não é tudo, pois ao mesmo tempo ele tem (ou pode ter, conforme a situação) uma parte fonética e uma semântica, a qual não é necessariamente igual à imagem motivadora original. Trata-se, portanto, de símbolos complexos, o que atesta para o seu caráter linguístico e completamente distante dos desenhos dos homens das cavernas.

Para que se tenha uma idéia mais concreta, reproduzimos aqui um exemplo retirado de leitura de uma linha em hieroglifos hititas:

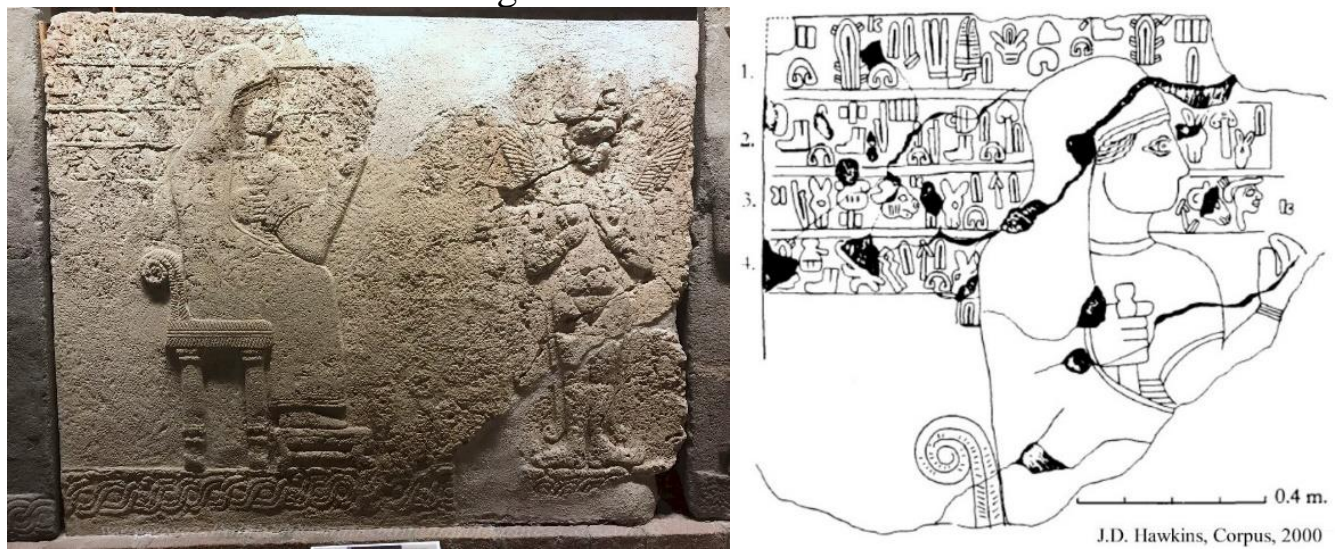

Figura 2 e Figura 3. Monumento hitita de Karkamis (hoje no Museu da Civilização da Anatólia, na Turquia) e a respectiva transcrição de parte de seus hieroglifos.

Fonte: https://www.hittitemonuments.com/karkamis/kargamis65.htm

\footnotetext{
${ }^{2}$ Weeden e outros estudiosos de hieroglifos trabalham apenas com o conceito dos logogramas (anotado em caixa alta na sua própria língua materna) para simplificar a transliteração e tradução de textos (cf. WEEDEN, p. 84). Cf. as figuras 2 e 3 para ver a forma concretizada do hieroglifo PÉ.
} 


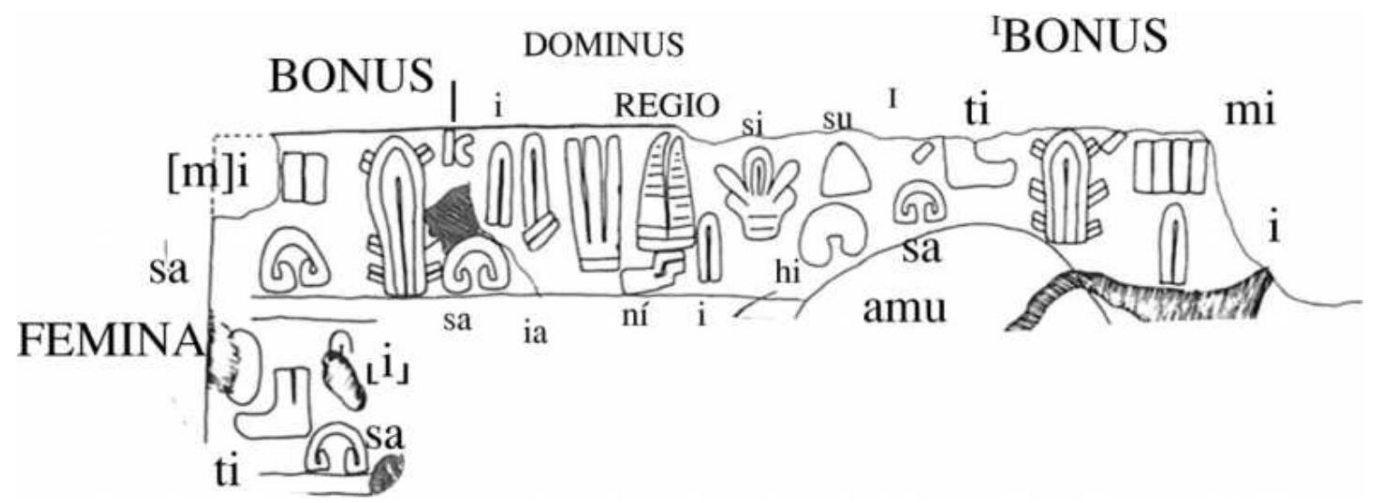

Figura 4. Detalhes da primeira frase do texto em hieroglifos acima com sua leitura (cf. WEEDEN, 2014, p. 88).

\section{EGO- $m i-i$ IBONUS- $t i-s a{ }^{\mathrm{I}} \boldsymbol{s} u-h i-s i-i$ REGIO- $n i$-DOMINUS- $i a-i-s a \mid$ BONUS- $[m] i-s a$ FEMINA- $t i-i-s a$}

amu=mi Was(a)tis Subisi REGIO-ni-DOMINUS-iais wasamis wanatis.

I am Was(a)ti the dear wife of Suhi the country-lord.

Figura 5. Transliteração linear com tradução de Weeden (2014): "Eu sou Was(a)ti, a boa esposa de Suhi, o senhor local".

Com esses exemplos acima, creio que deva ficar clara, pelo menos, a diferença formal entre a escrita hieroglífica e a ideogramática moderna. Em termos de forma, os hieroglifos são muito mais próximos aos pictogramas que aos ideogramas chineses. No entanto, em termos de significado, os hieroglifos também são complexos, podendo ter uso meramente fonético ou remeter a um valor nocional.

\section{A "escrita conceitual" versus os ideogramas}

Retomando a discussão sobre os ideogramas, vê-se que o problema acarretado pela etimologia dessa palavra (i.e. "escrita conceitual") tem gerado dificuldade para sua adoção, pois implicam uma visão errônea da língua que usa ideogramas.

Mesmo entre linguistas que trabalham com línguas antigas, vemos que, por exemplo, Gelb (1963 apud KUDRINSKI; YAKUBOVICH, 2016, p. 54) criticou o uso desse termo para se referir à escrita cuneiforme, pois em seu entendimento essa palavra deveria ser reservada para sistemas de "escrita primitiva", uma vez que denotam palavras mais que noções. Ou seja, Gelb entendia os ideogramas como algo mais próximos aos pictogramas. Devido a essas críticas de Gelbe, Kudrinski e Yakubovich afirmam que o uso do termo "ideograma" para a escrita cuneiforme foi praticamente abandonado em favor do termo mais genérico "logograma" e podemos afirmar que o mesmo pode ser notado em alguns estudos contemporâneos sobre as línguas chinesa e japonesa.

No entanto, a troca de "ideograma" por "logograma", ao meu ver, apenas tenta fugir de um erro do senso comum, sem acrescentar muito à diferença que existe entre as várias escritas não-fonéticas.

Hoje já se sabe que nenhuma escrita humana é puramente conceitual, nem mesmo os próprios hieroglifos, como já demonstrado acima. $\mathrm{O}$ mesmo vale para a escrita desenvolvida na China e para a famosa escrita cuneiforme.

A escrita cuneiforme dos sumérios funcionava, inicialmente, de forma similar aos hieroglifos. Entre seus registros mais antigos no século XXXII a.C. e a invasão da Suméria pelos acádios, no século XXII a.C., porém, os símbolos, escritos com cunhas, passaram de 
puramente motivados e conceituais (i.e. pictogramas) a fonogramas, isto é, adquiriram um valor primordialmente fonético (cf. CLAIR; BUSIC-SNYDER, 2009, p. 16-18; PUHVEL, 2019).

Por ter se tornado fonética, a escrita cuneiforme permite que hoje se consiga decifrar como eram lidos muitos dos pictogramas, logogramas e hieroglifos de outras línguas antigas da Mesopotâmia e arredores. Acádios, hititas, hurritas e outros povos escreviam em cuneiforme suas línguas, fazendo um uso primordialmente fonético, ou então, em textos bilíngues, indicavam acima de hieroglifos a leitura em cuneiforme. Essa escrita contou com grande prestígio e foi usada por muitos povos até ser completamente desbancada em importância e, por fim, abandonada em troca do sistema alfabético dos fenícios no primeiro milênio antes de Cristo.

Esse fenômeno que aconteceu no Oriente Médio cinco mil anos atrás em muito se assemelha ao que aconteceu no Extremo Oriente com a adoção dos caracteres chineses por povos das regiões próximas à China, como os japoneses.

Ao adotarem a escrita de uma língua que não se parecia com a sua ${ }^{3}$ e que não era fonética, os japoneses começaram a fazer um uso fonético desses caracteres que, com o tempo, derivou em seus dois silabários. Algo similar ocorreu com os coreanos e seu alfabeto, também inspirado nos ideogramas chineses. Apesar disso, o uso dos ideogramas também continuou sendo feito, num fenômeno curioso, motivo pelo qual uma palavra como 漢字 continue possuindo nesses três países sua própria forma de ser lida: hànzì, kanji e hanja (respectivamente em mandarim, japonês e coreano).

Como dito anteriormente, acredita-se hoje que nenhuma escrita plenamente desenvolvida seja apenas conceitual. Puhvel (2019) afirma que a escrita cuneiforme possuía um sistema de palavra-sílaba, usando seu inventário de ideogramas e signos fonéticos, num sistema similar ao dos hieroglifos e hititas etc. No entanto, para a maioria das escritas conhecidas, a cuneiforme inclusive, um forte processo de "fonetização" aconteceu, enquanto, no caso da escrita chinesa, acredito que seja possível afirmar que o caráter conceitual ainda permanece mais presente por sua forma.

Nem por isso, pode-se dizer que não há fonetização no chinês, muito menos em outras escritas derivadas desta. Sobre o chinês, Olson (2014) explica que,

\begin{abstract}
embora seja possível inventar signos para representar objetos comuns, muitas palavras não são facilmente retratáveis. Para representar essas palavras, o princípio fonográfico foi adotado. Pegou-se emprestado uma grafia que retrata um objeto qualquer para escrever uma palavra diferente que, por acaso, soa parecido. Através dessa invenção, os chineses se aproximaram da forma de escrever dos sumérios. Entretanto, por causa do enorme número de palavras chinesas homófonas, aplicar o princípio fonográfico em toda a língua resultaria em um sistema de escrita em que muitas palavras teriam a mesma leitura - ou seja, uma mesma palavra escrita seria muito ambígua.
\end{abstract}

Essa explicação sobre o excesso de palavras homófonas na língua chinesa é comumente relatada também a respeito da língua japonesa, na justificativa de por que ainda usam os ideogramas. De fato, em termos de escrita, a saída adotada foi o desenvolvimento de grafemas compostos, em que uma parte remete ao significado e outra ao som.

A solução para o problema da ambiguidade de caracteres, adotada em c. 213 a.C. (durante o reinado do primeiro imperador Qin, Shihuangdi), foi distinguir duas palavras de mesmo som e representadas pela mesma grafia pela adição de uma outra grafia, a qual daria uma pista do significado pretendido. Essas grafias complexas ou caracteres consistem em duas partes, uma sugerindo o som e a outra parte o

\footnotetext{
${ }^{3}$ A língua chinesa (em todas suas variantes, i.e. cantonês, mandarim etc.) e a língua japonesa (e seus dialetos) não pertencem ao mesmo tronco linguístico. O japonês é considerado uma língua isolada. O coreano também é uma língua isolada.
} 
significado. O sistema foi, então, padronizado de modo a aproximar-se do ideal de uma grafia para cada morfema ou unidade de significado na língua. (OLSON, 2014).

Por esse motivo, os caracteres ainda hoje utilizados podem ser distinguidos como pertencentes a três categorias: pictográficos (象形文字), ideográficos (指示文字) e os compostos, sendo que esses podem ser compostos por idéias (会意文字) ou fonéticoideográficos (形声文字), por vezes chamados de fonologogramas.

Como se percebe pela nomenclatura, os ideogramas pictográficos são os do tipo mais simples, derivados da observação direta e subsequente padronização da forma. É importante notar, porém, que eles não são simples "desenhos" nem "pictogramas", pois, como vimos na seção 2, existe uma padronização formal muito grande que faz com que esses caracteres sejam muito mais fixos e regulares que, por exemplo, símbolos de masculino e feminino em portas de banheiro. Observe-se a situação do ideograma pictográfico para "árvore":

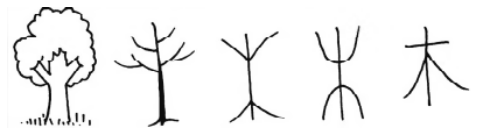

Figura 6. Desenhos de árvore (1 e2) e evolução do ideograma pictográfico para "árvore" (3 a 5). Fonte: SHIN NIHONGO NO KISO, 1992, p. 12.

As duas primeiras imagens são apenas desenhos, mas as imagens 3 e 4 são formas antigas desse ideograma. A última é a versão atual dele, a qual é também a única encontrada e aceitável em textos contemporâneos (木). Isso quer dizer que não é possível usar nenhuma das outras versões ao se escrever em chinês ou japonês.

Embora haja diversos ideogramas pictográficos em uso hoje, eles não apenas são a minoria absoluta dentro do corpus das línguas chinesa e japonesa, como é facilmente perceptível que o grau de desenvolvimento desde a observação do objeto inicial faz com que a motivação por trás daquele símbolo esteja muito distante para o leitor contemporâneo. Observem-se mais alguns exemplos:

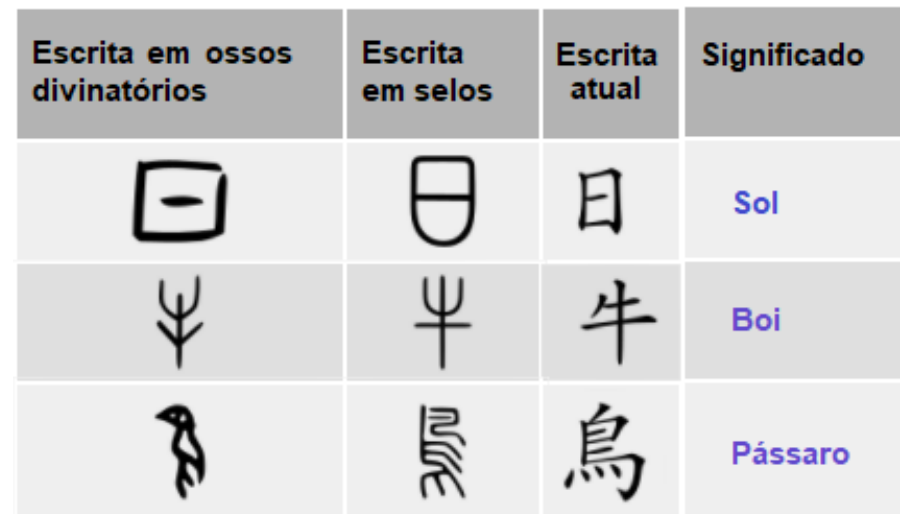

Tabela 1. Evolução desde os espécimes mais antigos (ossos divinatórios), do séc. XVIII a.C. até hoje. (Adaptada de: https://en.wikipedia.org/wiki/Chinese_character_classification).

É importante notar que a simplificação e padronização dos caracteres é uma condição sine qua non para o estabelecimento de um sistema de escrita eficiente. A própria escrita cuneiforme passou por esse processo em seu curso. A título de comparação trazemos os mesmos exemplos para o cuneiforme ao longo dos séculos: 


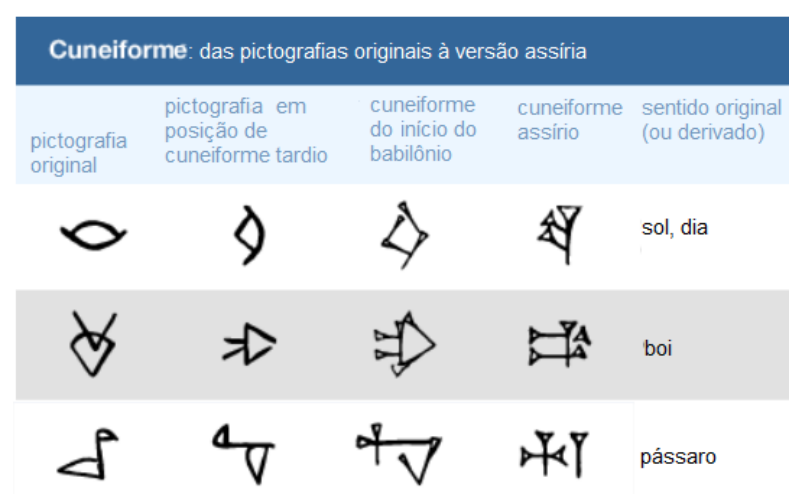

Tabela 2. Evolução da escrita cuneiforme ao longo de dois mil anos. Adaptada de Puhvel (2019).

Os ideogramas ideográficos, embora não sejam derivados de observação de objetos, também são extremamente simples e, por isso, poderiam ser considerados também "primitivos". Eles também fazem parte desse grupo mais antigo de caracteres, os quais hoje constituem a menor parte dos ideogramas chineses e japoneses. Os números um, dois e três caracterizam bem esse grupo: - , 二, 三.

Por fim, temos os ideogramas compostos. Dentro deste grupo, há ainda dois subgrupos. O primeiro é o por composição de idéias. Na seção anterior, tínhamos mencionado o ideograma de “claro” (明) que é composto pela junção do “sol” (日) e da “lua” (月). Outro exemplo simples é o de "descanso" que une as idéias de um homem sob uma árvore: 休. Esse segundo exemplo, porém, serve para identificarmos um fenômeno importante que ocorre à medida que os ideogramas compostos se proliferaram: a simplificação de um dos caracteres em uma forma reduzida, chamada de radical. Em 休, temos do lado direito a árvore, em sua forma completa, mas o ideograma de homem, do lado esquerdo, tem aí uma de suas versões reduzidas (o radical chamado de ninben), pois sua forma normalmente é 人.

Desse modo, chegamos aos caracteres mais complexos existentes, que formam a grande maioria do total dos ideogramas e cujas composições abandonam a observação da natureza e a simples associação de idéias em nome de um grau maior de eficiência linguística.

Nesses caracteres, parte da grafia remete, ainda que vagamente, ao sentido do signo e outra parte, ainda que sem exatidão, a seu som. Não há acuidade nem fonética, nem no significado, mas essas letras já são bem mais "fáceis" de ler, para os versados nessas línguas. Por exemplo, em 問 (perguntar), a parte de dentro é o ideograma de boca (口), ou seja, a parte que se relaciona ao significado, e a parte de fora dá a leitura ${ }^{4}$ mon, em japonês, que é exatamente a mesma do ideograma 門 (portão). Ou seja, a leitura de "portão" foi perfeitamente aproveitada em "perguntar". Isso nem sempre acontece, como vemos na versão chinesa desses ideogramas, em que o primeiro se lê wèn e o segundo mén, mas se tratam leituras similares que, portanto, funcionam como pista mnemônica para o leitor.

Note-se ainda, a título de comparação com a evolução dos hieroglifos e da escrita cuneiforme, que, no caso do Japão, dois silabários próprios nasceram dos ideogramas. Esses silabários hoje são usados concomitantemente com os caracteres chineses para escrever diferentes tipos/partes de palavras japonesas, numa conjunção de grafias: kanji (ideogramas), hiragana (silabário derivado da escrita cursiva dos ideogramas) e katakana (silabário derivado de abreviações dos ideogramas). De forma simplificada, pode-se dizer que os ideogramas

\footnotetext{
${ }^{4}$ Observe-se que muitas vezes há mais de uma leitura para um mesmo ideograma. Nestes exemplos, a título de simplificação, cito apenas uma.
} 
marcam a parte dura, nocional das palavras; o hiragana é usado para palavras não-nocionais ou a parte "flexionável" das palavras. O katakana é relegado a usos excepcionais, como para marcar palavras estrangeiras. Para um exemplo, observe-se uma palavra moderna como 消しゴ $\Delta$ (borracha), a qual usa os três tipos de escrita simultaneamente.

Esse sistema de escrita permitiu de modo mais eficiente aos japoneses indicar em sua escrita flexões de sua língua que não existem em chinês e que, portanto, não eram facilmente indicáveis pelo uso só dos caracteres chineses. Por exemplo, a conjugação verbal em japonês é bem mais variada que em chinês. Aproveitando o verbo já citado "perguntar", em japonês: 問 う (presente afirmativo), 問わない (presente negativo), 問った (passado afirmativo), 問わな かった (passado negativo). Em chinês, no entanto, o passado (了) e a negativa (没) são indicados por dois ideogramas monossilábicos, marcando uma expressão final mais curta. Além disso, o uso da marca da passado ou da negativa chinesa não contemplaria os verbos irregulares japoneses, fazendo com que um mesmo caractere tivesse que ser lido de inúmeras maneiras, dependendo do verbo em questão.

\section{Considerações finais}

Revejamos então os diversos nomes propostos para os signos nas escritas não-fonéticas.

Em primeiro, parece-nos claro que pictogramas são imagens que, embora comuniquem sentido, parecem se encontrar num estágio ainda não optimizado de comunicação linguística. Pouco padronizados, pouco simplificados, os pictogramas não são eficientes para a formulação de textos, por exemplo, embora já não sejam simples desenhos. Embora haja abstrações, os pictogramas ainda são muito presos à representação da Natureza e de ações concretas.

Os hieroglifos, sendo muito motivados ainda, são signos que inicialmente parecem próximos à idéia de pictograma, mas, como se mostrou, nos textos escritos com hieroglifos percebemos há duas características que os distinguem claramente daqueles. Primeiramente, já há um nível de abstração inegável em relação aos pictogramas, atestando para a distância entre o objeto de motivação original e o desenho. Isso permite, por exemplo, que haja caracteres para conceitos abstratos como "bom", "esposa" etc. para além de uma simples representação da Natureza. Em segundo, vê-se que os hieroglifos já podem ser usados de forma fonética. Este último é um passo fundamental para a optimização da ligação entre a fala e a escrita, afastando mais e mais a escrita da simples pictografia.

Os hieroglifos, entretanto, ainda são claramente muito pictográficos e pouco concisos em sua forma. Embora com o passar dos séculos, formas mais simples tenham sido desenvolvidas, as formas clássicas (apresentadas aqui), ainda são muito imagéticas. Esse é um ponto que os afasta, por exemplo, do aspecto dos ideogramas modernos.

Aqui, por ideogramas, tratamos basicamente dos caracteres chineses, utilizados também por outros países da Ásia. Os ideogramas tiveram seu início também na pictografia, mas ficou claro que sua evolução gráfica os afastou tanto desses, quanto dos hieroglifos em sua fase clássica. Embora sobrevivam ainda diversos ideogramas de fundo pictográfico ou conceitualmente simples, a grande maioria deles já é formada por composição complexa, incluindo também um caráter de sugestão fonética.

Note-se que o termo logograma, por sua vez, foi proposto como termo abrangente para os grafemas que identificam uma única palavra. Essa definição permite que tanto pictogramas e hieroglifos, quanto ideogramas possam ser identificados como logogramas em certas situações. No entanto, a complexidade dos sistemas de escrita que usaram e ainda usam esses grafemas provaram que muitas vezes os grafemas não equivalem apenas a uma palavra - seja porque remetem a várias idéias diferentes, seja porque precisam ser acompanhados de outros grafemas para formarem algo, ou porque estão sendo usados com valor fonético. 
Esse fato torna o termo logograma um termo genérico, guarda-chuva para os grafemas não-fonéticos, mas apenas em uma situação muito específica que parece um tanto rara na análise de textos inteiros. O resultado dessa insuficiência, então, é que, principalmente entre os estudiosos de antigas escritas, mais termos têm nascido, como por exemplo "heterograma".

Não vamos nos estender aqui na análise de outros termos, até por atualmente estarem mais restritos a estudos mesopotâmicos, mas é interessante notar que a proposta de Kudrinski e Yakubovich (2016, p. 55) para a definição de "heterograma" parece aproximar-se, por exemplo, do antigo uso que os japoneses deram para os ideogramas antes do desenvolvimento de seus silabários (os man'yôgana,). Pesquisas futuras nessa linha, então, poderiam ser interessantes para o estabelecimento de um termo mais adequado àquele momento histórico, pelo menos.

Por hora, concluímos que o uso de "ideograma" parece contemplar bem a especificidade dos signos linguísticos chineses e japoneses, que, por mais que seja diferente entre essas línguas, se distancia da situação gráfica, fonética e conceitual da dos outros termos analisados.

\section{Referências}

CLAIR, Kate; BUSIC-SNYDER, Cynthia. Manual de Tipografia: a história, a técnica e a arte. São Paulo: Bookman, 2009.

GERBER, Ignacio. Figuras rupestres: arte e/ou escrita? Ide, v.32, n.48, São Paulo, jun. 2009. Disponível em: <http://pepsic.bvsalud.org/scielo.php?script=sci_arttext\&pid=S010131062009000100004>. Acesso em: 8 fev. 2021.

KUDRINSKI, Maksim; YAKUBOVICH, Ilya. Sumerograms and Akkadograms in Hittite: Ideograms, Logograms, Allograms, or Heterograms? Altorientalische Forschungen, v. 43, n. 1-2, p. 53-66, 2016. DOI: https://doi.org/10.1515/aofo-2016-0018.

LI, Xueqin et al. The earliest writing? Sign use in the seventh millennium BC at Jiahu, Henan Province, China. Antiquity, mar. 2003, v. 77, n. 295, p. 31.

OLSON, David R. Chinese writing. Encyclopedia Britannica. 14 mar. 2014. Disponível em: <https://www.britannica.com/topic/Chinese-writing>. Acesso em: 6 fev. 2021.

PUHVEL, Jaan. Cuneiform. Encyclopedia Britannica. 13 mar. 2019. Disponível em: <https://www.britannica.com/topic/cuneiform>. Acesso em: 6 fev. 2021.

SHIN NIHONGO NO KISO: kanji workbook 1. Tokyo: 3A Corp, 1992.

SOARES, Magda Becker; BATISTA, Antônio Augusto Gomes. Alfabetização e letramento. Belo Horizonte: Ceale/FaE/UFMG, 2005.

TANG, Didi. 5,000-year-old primitive writing generates debate in China. NBC News. 11 jul. 2013. Disponível em: <https://www.nbcnews.com/sciencemain/5-000-year-old-primitivewriting-generates-debate-china-6C10610754>. Acesso em: 8 fev. 2021.

WEEDEN, Mark. Anatolian Hieroglyphs: Logogram vs. Ideogram. In: GORDIN, Shai (ed.). Visualizing Knowledge and Creating Meaning in Ancient Writing Systems. Berlin: 
PeWe-Verlag, 2014. p. 81-100. (Berliner Beiträge zum Vorderen Orient 23). Disponível em: <https://eprints.soas.ac.uk/18204/1/BBVO-23_Weeden-2.pdf>. Acesso em: 8 fev. 2021. 